\title{
Early Care And Education: Our Social Experiment
}

Molly H. Minkkinen, (E-mail: mminkkin@d.umn.edu), University of Minnesota, Duluth

\begin{abstract}
Today children in the United States are living a social experiment with unknown consequences. According to a report by Carnegie Corporation (2002), $72 \%$ of infants and toddlers spend more than 35 hours per week in care outside of their homes. An estimated 10 million children under the age of 4 are cared for by people other than their parents (Shore, 2002); a number that is higher than any other time in our history. The importance of this social experiment is exacerbated by the number of substandard childcare programs in our country (Bergmann \& Helburn, 2002). Recent neurobiological research has provided a wealth of data that supports the need for high quality programs. The correlation between sensitivity periods of neural development, neural plasticity, neural chemical reactivity, and early experiences are critical issues that demand that early childhood educators collectively evaluate the programs children "live" in (Diamond, 1998). The current knowledge base in the development of young brains has provided the opportunity to influence the outcome of our social experiment
\end{abstract}

\section{INTRODUCTION}

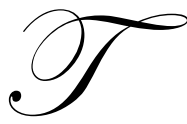

he past 20 years has brought about a shift in the social experience of young children in the United States. Children are no longer in the care of stay at home moms and neighborhood friends. Instead they spend their childhood in institutionalized and organized care. According to The Family and Work Institute, $72 \%$ of America's children under the age of one were in non parental care in 1994. By the time children are 4 year olds the number was $86 \%$ (Shore, 2002). The total number of children in nonparental care more than doubled between 1990 and 1994; with 5 million children in care in 1990 and 10.3 million children in care in 1994 (Shore, 2002). Further studies have found that children who attend child care programs in the US are in attendance for an average of 35 hours per week (Shore, 2002).

While the number of children in care outside of their homes continues to increase the quality of care becomes an issue of concern. Research released by the Carnegie Corporation. (2001) states that $12 \%$ of the child care programs in the US provided positive experiences and support for young children, while $35-40 \%$ were found to be detrimental to the health and wellbeing of children.

The fact that there are large numbers of children spending the majority of their waking time in care outside of their homes is a significant issue in the US. US children are living out a social experiment with unknown results. The majority of today's children are experiencing a childhood that is different from the childhood of the past. A large number of today's children spend their days with people who do not love them unconditionally, people who come and go from their lives at a time when their brains are organizing attachment patterns. These attachment patterns have a significant affects on the child's ability to acquire and retain relationships throughout life.

Research findings from economists and child care advocates have found that quality care is inherent in the care provider, whether the care provider is a grandmother, child care teacher, or neighbor. In order to ensure that care is of high quality there are critical characteristics that need to be present. They are education, specialized training and a positive attitude about their job and the children they work with. Employment factors such as adequate pay, child to staff ratios, and group size contribute to the attitude and subsequent retention of child care staff. Unfortunately the 
issue of low quality child care persists due to the fact that the child care industry is plagued high staff turn over which is the direct result of inadequate pay, high child to staff ratios and large group sizes (Shonkoff and Phillips, 2000).

The need to change is obvious. As we initiate change we will be in the company of professionals who are new to the cause of quality care and early childhood development. Neurobiologist, sociologist, and economists are joining early childhood educators and child psychologists to bring expertise from their respective fields to the importance of early care and brain development. The current knowledge base generated through these new professional relationships has provided the opportunity to influence the outcome of our social experiment

\section{THE BIOLOGY OF EARLY DEVELOPMENT}

Research in the area of infant development has endless facets of investigation. No single facet of research is more important than another and all of the findings work in a synchronous fashion to facilitate our understanding of child development.

Research on child development has proliferated across the centuries. Infant characteristics like attention, digestion, and behavior are among the areas studied. The research findings in these and many other areas have deepened our understanding of how infants' respond to their environments, and to the people who care for them. The findings from research have also led to changes in strategies for interacting with infants in the medical, educational and parenting realms.

One area of research interest in the past decade has focused on the issue of infant brain development. In most cases the goal of the research has been to attempt to answer long standing questions that past scientists and researchers were prevented from studying because of a the limitations of technological advancement and expertise. The research focused on the biological function of cognition, how chemical reactivity influences brain function, the biological origin of temperament, and the biological impact of breast feeding on early brain development. Advancements in science and technology along with the work of past researchers have led to a time when many hard to answer questions about infant brain development are ripe for investigation.

Researchers Gunnar and Barr (1998) describe the development of the architectural process as the biological growth and differentiation of the developing brain. They suggest that the development and migration of the neurons in the developing brain consist of a series of biological events that proceed in a relatively well-ordered but overlapping sequence. This sequence consists in the birth and migration of cells, the growth of the axon, and the formation of dendrites which allow connections among neurons, the formation of the synapse that allow the information flow across neurons and then the mylenation that speeds up the transmission of neural impulses. The repeated process of this biological sequence is the precursor to the circuit development of the brain that will be discussed later.

Gunnar and Barr state (1998) that axon development is largely complete by birth in full-term infants. Dendritic growth, synaptic function, and mylenation are largely postnatal events. Most of the brain growth in these areas has been found to take place during the first two years of the infant's life.

Diamond, (1988) suggests that the brain has a use it or lose it structure. She states that we are born with an overabundance of neurons and dendrites, and that during the prenatal period there is a pruning process that begins. This pruning is the result of the experience dependent circuit development of the neural pathways. The neurons that are used remain, while those that are not die off (Pally, 1997). The neural circuit that Diamond describes is the foundation the constructs that substantiate learning throughout the infant's life. Gunnar et al. (1998) indicates that findings from animal research show that early experiences program the brain's neurological circuits in ways that affect later cognitive competence, emotional responding, and activities of physiological systems that orchestrate reactions to stress and challenge. 


\section{BRAIN PLASTICITY AND EARLY LEARNING}

Neural plasticity describes the flexibility of the neural circuitry to adapt and adjust to stimuli. According to Diamond (1998) neural plasticity is essentially neural flexibility. Diamond (1998) states that neural plasticity has the same functional resilience, and pliancy of living silly putty. Diamond goes on to say that "more than any other organ, the brain can be shaped by stimulation and use, by disease, and trauma, by dull routine and disuse into a center of thought, sensation, and regulation most appropriate for a given individual's life" (p. 58). Healthy brain development has the presences of both neural hardwiring and neural plasticity. Pally states (1997) that more plasticity exists in cortical circuits where new dendrites can grow and synaptic connections can continue to be made throughout life. An example would be that cortical function such as vocabulary and math have a lot of plasticity. People can continue to learn a number of words for the same concept and a number of solutions to a problem. On the other hand, the subcortical limbic "emotional" circuits that develop in infancy have less plasticity and therefore may have a longlasting effect on subsequent psychological development. It seems that these are the circuits that, through repetitive performance create permanence (hardwiring), allow children to form and maintain attachments to their parents over the long period of their development and to seek familiar reliable sources of safety and comfort.

Gunnar (1998) and Diamond (1998) add to this theory by suggesting that many aspects of brain development are activity dependent (use dependent), and thus incorporate experience as part of the basic program for growing a brain. They also say that experiences early in life do appear to influence how the child reacts to later experiences and how the brain processes and profits (or fails to profit) from experiences throughout life.

\section{CHEMICAL REACTIVITY}

According to neurobiologists Johnson (2000) and Diamond (1998) we are born with about 100 billion nerve cells in our brains call neurons. Each of the 100 billion neurons has the capability to generate a chemical response that is significant to the overall function of the brain. Each neuron is made up of a cell body, dendrites, an axon, and terminals. The terminals are found at the base of each of the axons and house a myriad of chemicals called neurotransmitters. Neurotransmitters work with the neurological system to send messages that work to regulate the neural system. Some familiar neurotransmitters are; dopamine, serotonin, adrenaline, and cortisol.

Neurotransmitters are released from a terminal and enter an available receptor on a branch of a dendrite. This transmission is based on information input through the senses. There is a reticular activator at the base of the brain stem that acts as a switching station between information input and chemical release. As the body experiences sensory information the brain identifies the activation needed on a chemical level. A specific chemical (neurotransmitter) will be released and will in-turn activate a physiological response in the body. An example of this is if a person smells smoke while sitting in his/her living room his/her brain assesses the appropriateness of the smoke in the living room. The information about the smoke enters the brain system via the olfactory senses. The brain then determines the chemical reaction that best facilitate the survival of the person. The neurotransmitter, adrenaline will be released from the terminals of the axons and enter receptor sites on the branches of dendrites. There will then be a physiological response. The presence of adrenalin will initiate an increased heart rate, more blood will be sent to the muscles, and the person will have a heightened sense of alertness. Due to the chemical response the person will, physiologically, have the ability to get help and possibly put out a fire.

According to Johnston (1995), neurotransmitters are present in the developing brain while still in utero. His research indicates that the developing brain is very responsive to these chemicals and the presences of them in the developing brain are tied to infant behavior.

\section{BRAIN DEVELOPMENT AND THE ROLE OF EARLY EXPERIENCES}

Pediatric neurologist, Harry Chugani who studies early brain development notes "there is no doubt that experience molds the young brain. The early years determine how the brain turns out" (Schore, p.1, 2002). He goes on to make clear that the child's potential is determined in the early years - from the first moment of life to countless hours spent in day care. He says "these are the years when we create the promise of a child's future. This is when we 
set the mold". Many scientists have said that kindergarten is not the starting point of the child's brain development. They say that by kindergarten the process is half over (Schore, 2002).

Although the work of Schore and Chugani and others make clear the obvious movement today in the sciences to include early brain development, there is a well paved road to the current practice of child care and neurobiology that is rich in history.

In an article titled "Neonatal Neurology, Past Present and Future: A window on the brain", the author, Lily Dubowitz and her colleagues describe the historical journey of the study of infant brain development. Dubowitz et al. (1995) state that the first examination of the brain had taken place in the 1940's and 50's. The study of the brain at the time was aimed at evaluating the neurological state of the full term infant. The first examination was conducted by Andre'-Thomas and Saint-Anne Dargassies. The examination mainly involved the evaluation of passive and active tones and defined in detail various primitive reflexes. The findings of the examination mapped out the maturation of the neurological features in premature infants of various gestational ages and were able to show that the development characterized related to the maturity and not the size of the infant.

Dubowitz et al. (1995) write further about the history of infant brain research by citing the work of Prechtl of Holland. Prechtl's research followed that of Thomas and Dargassies. In the 1970's. Prechtl developed an examination which concentrated on the neurological responses of the full-term infant. The aim of the research was to take into account the behavioral state of the newborn. The findings were able to demonstrate that many of the neurological signs in a newborn were dependent on the state of alertness at the time the newborn was evaluated.

Dubowitz et al. (1995) continue their review of historical research in the area of infant brain development with the work of T. Berry Brazelton in the early 1970's. Brazelton developed a behavioral examination which was based to a large extent on an earlier examination developed by K.F. Graham in the 1950's. The items included tests that measured motor activity and strength, responsiveness to auditory stimuli as well as measured irritability and tension in infants. It also aimed to evaluate the interaction between the newborn infant and its caretakers (Dubowitz et al., 1995).

The work of Thomas \&Dargassies (1952), Prechtl (1977), Brazelton (1972), and others were successful in creating an understanding of the human brain function, which has in-turn, provided insight into early brain development. The synthesis of their work has identified behavioral benchmarks in brain development that show stage and phase related consistencies among developing infants. The measures, although empirical, left questions that were technologically unanswerable.

The Dubowitz et al. study of live infants examined the incidence, timing and evolution of the brain lesions in the neonatal period. The researchers were able to follow the evolution of the lesions into infancy. The findings from this work is significant in the development of an understanding of development of brain lesions in live infants. Discussions of these findings are significant to the field of early childhood education, child development and other related fields because they suggest that early neurological brain function is essentially the creation of cognitive constructs that become the function of sight, language, emotional response, and creativity.

\section{THE IMPACT OF QUALITY CARE ON THE SOCIAL EXPERIMENT}

Our societal experiment has two important components. First, data from the HICHD suggests that there are large numbers of children are in substandard nonparental care in the US (2001). Second, scientific research provides us with information that indicates that brains begin developing before birth and have significant developmental growth between birth and five years of life. These two factors, although independent, they are critically inter-related.

Quality of child care in our country not only affects children but also parents, and society as a whole. The quality of care children experience affects areas of development which include; social, emotional and cognitive development. The Cost, Quality, and Child Outcomes study found that children who had attended higher quality child care centers performed better overall at the end of second grade than children who had attended lower quality child 
care centers. (Helburn, 2002). The National Institute of Child Health and Human Development (NICHD) study also found that sensitive and responsive caregivers are important to children's development. After taking into consideration home environments and children's attributes, children in better quality care tend to score higher on cognitive tests (Helburn, 2002). Parents are affected by the quality of child care in many ways both personally and professionally. Personally, parents find peace in the belief that their children are experiencing the same heartfelt attention from the people who care for them. Quality care also affects a parent's ability to work reliability and focus on their jobs. Having a level of security about the quality of care their children are receiving while they are at work helps parents focus on their work and be more productive employees. Society is affected by the quality of child care due to the fact that the experiences children have early in their lives affects what kind of adults they will become. The quality of a child's early care helps determine how psychologically secure, emotionally mature and economically productive they will be as adults.(Helburn, 2002, p.3).

According to neurobiologist Marion Diamond (1998), developing brains require quality care to assure they have to tools needed to be productive adults. There are specific elements to quality care according to Diamond and they are: environments which are supportive and nurturing, free of undue stress, provide proper nutrition, allow children to assess there own learning, and encourage children be active participants in their own learning. Children need to be cared for by people who understand the significance of these elements on both an educational and biological level. Quality child care is dependent on early childhood educators having the educational background necessary to understand not only why elements like the ones Diamond described are essential to quality programming but, also how to design and implement environment that support them. Quality child care will exist when parents, educators and policy makers understanding the biological underpinnings of physical, emotional and cognitive development. The impact of quality care will be found in the adults who are products of a child care system that understood and met their needs as young children. These will be Children who grow up to be responsible citizen in any culture.

\section{OUR RESPONSIBILITY}

We are all participants in this experiment whether you are a parent, grandparent, politician, teacher, business owner, or community member. We all have a stake in the positive outcome of this experiment. There is substantial research data that indicates that there are implications for not nurturing early neurological development and that children do not thrive in negative environment and substandard care. We also know that a person's social, emotional and cognitive development is impacted by the care children receive early in life. We also know that the large number of children identified by the National Institute of Child Health and Human Development who are in low quality child care will grow up to vote, own businesses, teach, and parent.

The information is before us, now we all need to take stock in a system that is failing. A system that serves a portion of our population that does not have a voice. The children will never write to their legislator to demand change. They will never organize to ensure better child care services. They will never ask the government for more qualified teachers and care providers. They are silent subjects in this experiment. The system will not change until adults step in and demand the change that the children deserve and have no language to ask for.

\section{REFERENCES}

1. $\quad$ Brazelton, T.B (1973) Neonatal behavior assessment scale. Clinical Development Med, 50.

2. Carnegie Foundation (1995). Starting Points, Carnegie Foundation, N.Y.

3. Diamond, M., Hopson, J. (1988) Magic trees of the mind. New York: Penguin.

4. Dubowitz, L. M., Cowan, F., Rutherford, M. Mercuri, E., Pennock, J. (1995). Neonatal neurology, past present and future: A window on the brain. Brain and Development, 17, 22-30.

5. Gunnar, M. R., Barr, R.G. (1998). Stress, early brain development, and behavior. Infants and Young Children, 11(1), 1-14.

6. Gunner, M.R., Brodersen, L., Nachmias, M., Buss, K., Rigatuso, J., (1996). Stress reactivity and attachment security. Developmental Psychobiology, 29 (3), 191-204. 
7. Helburn, S.W., Bergmann, B.R. (2002). America's Childcare Problem: The Way Out. New York: PALGRAVE.

8. J. Ehrle, G. Adams \& K. Tout. (2001). Who's Caring for Our Youngest Children? Care Patterns of Infants and Toddles. Washington D.C.: Urban Institute.

9. Johnson, M. (2000). Functional brain development in infants: elements of an interactive specialization framework. Child Development, 71(1), 75-81.

10. Johnston, M. V. (1995). Neurotransmitters and vulnerability of the developing brain. Brain and Development, 1995(17), 301-306.

11. Pally, R. (1997). How brain development is shaped by genetics and environmental factors. International Journal of Psychoanalysis, 78, 587-593.

12. Panksepp, J. (1998). Affective neuroscience: the foundation of human and animal emotion. New York: Oxford University Press.

13. Prechtl, H.F. (1977). The neurological examination of the full-term newborn infant: a manual for clinical use. Clinical Development Med, 63.

14. Shore, R. (2002). What Kids Need: Today's Best Ideas for Nurturing, Teaching and Protecting Young Children. Boston: Beacon Press.

15. Shonkoff J. P., Phillips, D. A., (2001). From Neuron to Neighborhoods. Washington D.C.: National Academy Press.

16. Thomas, A \& Dargassies, S.A. (1952). Etudes neurologique du tonus masculaire. Paris: Flammarion. 